\title{
EDUCAÇÃO INCLUSIVA: \\ JÁ SE FALOU MUITO \\ SOBRE ELA?
}

Anna Maria Lunardi Padilha'

Resumo

O objetivo deste texto é fornecer elementos para uma reflexão crítica acerca do que é hoje denominado "educação inclusiva”, especialmente em relação aos seguintes aspectos: o direito de todas as crianças e jovens a uma educação de qualidade; os equívocos da assim chamada inclusão; as lacunas na formação de professores e os aportes teóricos necessários à efetivação da educação para todos. O fato de existirem leis e resoluções que garantam a educação escolar universal, gratuita e laica para todos, inclusive para os deficientes, não vem garantindo o ensino de qualidade, ou seja, o aprendizado de conhecimentos acumulados historicamente pela humanidade. Pesquisas vêm demonstrando que a formação que professores do ensino fundamental vêm recebendo, tanto a inicial quanto a continuada, não responde às suas necessidades profissionais. Pensar a educação inclusiva exige conhecer a nossa realidade social e política, bem como dominar conhecimentos teóricos com rigor epistemológico acerca do desenvolvimento humano e do papel da escola como ato educativo. Tomamos como marcos teóricos a filosofia de Karl Marx e Friedrich Engels, a perspectiva histórico-cultural do desenvolvimento de Lev Semionovich Vigotski e a pedagogia histórico-crítica de Dermeval Saviani.

Palavras-chave: Educação Inclusiva. Direito à Educação. Formação de Professores.

1 Professora Titular da Universidade Metodista de Piracicaba. Doutora em Educação, Conhecimento, Linguagem e Arte, pela Universidade Estadual de Campinas/UNICAMP. 
Durante um debate sobre as propostas de inclusão escolar dos deficientes, ocasião em que estavam presentes cerca de 30 professores da rede pública de ensino e alguns alunos de pós-graduação em um município no interior do estado de São Paulo, ouviu-se de uma professora participante: "Os discursos sobre inclusão já estão se esgotando; só se fala nisso na escola e nas reuniões e nada acontece, de fato”. Em seguida, algumas vozes conversando, movimentos de corpos nas cadeiras, cabeças indicando ora afirmação, ora negação e alguns olhares indignados. Foram alguns segundos que me pareceram uma eternidade.

Aquele encontro fazia parte da pesquisa participante e colaborativa que desenvolvo e eu estava coordenando a discussão. Senti-me na obrigação de dar alguma resposta ou, pelo menos, oferecer uma direção ao debate. Não bastava repetir o discurso legal do direito de todos à educação, nem relembrar o caminho da construção legal do direito dos deficientes de estarem na escola, o que resultaria em prosseguir com a lista de documentos, declarações, diretrizes e planos sobre o tema, entre eles: a Declaração Universal dos Direitos Humanos (1948); o Pacto Internacional dos Direitos Econômicos, Sociais e Culturais (1966); a Convenção sobre os Direitos da Criança (1989); a Conferência Mundial sobre Educação para Todos (1990); a Convenção sobre os Direitos das Pessoas com Deficiência (2006); o Estatuto da Criança e do Adolescente (1990); a Declaração de Salamanca (1994); ou mesmo, referir-me à Constituição Federal de 1988 e às Diretrizes e Bases da Educação Nacional Lei n. 9.394/96 (1996). Ou ainda falar sobre a proposta de educação inclusiva oferecida no Caderno de Educação Especial da Secretaria de Educação Básica do Ministério da Educação (2012). De certo, todos que ali estavam já sabiam da existência da maioria desses documentos, além de outros das suas próprias Secretarias estaduais ou municipais de Educação. Talvez, por isso mesmo, o desabafo da 
professora. Este artigo dialoga com a professora investigando alguns desdobramentos de sua crítica.

Da Declaração dos Direitos Humanos, ao final da Segunda Guerra Mundial, até os dias de hoje, ainda engatinha nosso modo de conceber o humano como sujeito de direitos. Lembremos que o Estatuto do Idoso, por exemplo, na forma da Lei n. 10.741, de $1^{\circ}$ de outubro de 2003, ainda é pouquíssimo conhecido pelos próprios idosos e, de certo, pelos seus filhos e netos, o que significa que as cobranças também são diminutas; que o Estatuto da Criança e do Adolescente (1990) ainda é diuturnamente descumprido e que a Lei Maria da Penha (2006) ainda não é respeitada na maioria dos estados do território nacional. Somos um país violento (WAISELFISZ, 2014). Nada de que possamos nos orgulhar. O atendimento à saúde do povo brasileiro nos assusta, amedronta e nos mostra mais uma face da violência.

Por que seria diferente com a educação e a educação que se quer inclusiva? Não é diferente quando se pretende promover igualdade de condições para a educação, ou seja, quando se anuncia que os deficientes têm direito à educação nas escolas, que passam a ser denominadas de "escolas inclusivas", e que deveriam promover uma educação também denominada "inclusiva". Não sejamos ingênuos nem pessimistas. Há um árduo trabalho pela frente, em continuidade àquele que vem há pouco tempo antes de nós e que mobiliza muitos educadores e professores. Um país que expropria os pobres da participação dos bens materiais produzidos não pode ser um país que respeita o direito de todos à educação de qualidade, entenda-se, onde todos aprendam e se apropriem dos bens simbólicos construídos na história, de modo a participar das decisões políticas, sociais e econômicas. Parafraseando Saviani (2014), não se trata de aceitarmos uma "inclusão filantrópica" ou "piedosa". A filantropia denuncia a omissão do Estado, que joga para a sociedade todas as reponsabilidades, invertendo a lógica: no lugar de a educação ser direito de todos e dever do Estado, acaba sendo dever de todos e direito do Estado. As metas definidas para a educação nunca se cumprem ou se cumprem

Educação inclusiva: já se falou muito sobre ela? 
apenas muito lentamente. Fragmentada é nossa política educacional por ainda não se configurar como sistema à altura das necessidades de nosso povo (Idem).

\section{Os EQUívocos DA INCLUSÃO: CONCEITOS, PRECONCEITOS E ILUSÕES}

A matrícula de crianças e jovens nas salas de aula chamadas de comuns ou regulares - nomenclatura que gera o questionamento sobre o que seria uma sala de aula incomum ou irregular - muitas vezes significa, na realidade, a sua inclusão em um espaço que as exclui do processo de aprendizado e, portanto, de desenvolvimento das funções psíquicas superiores/culturais (VYGOTSKI, 1995). A inclusão das crianças nas ruas é causa e consequência da inclusão da violência em suas vidas e consequente exclusão da escola e da dignidade.

Penso ser esse raciocínio de fundamental importância na formação dos pesquisadores e trabalhadores da educação. Tais questões podem, igualmente, constituir-se marco teórico para as análises do cotidiano da sala de aula da “escola inclusiva”. Poderíamos denominar o pensamento que embasa nossas pesquisas e nossos estudos de pensamento crítico? De ato político intencional? De prática que organiza e articula teorias e ações? Que transformações podem acontecer, efetivamente, porque pesquisamos e publicamos nossos textos? Estamos falando de quê, quando falamos, por exemplo, em educação inclusiva e de qualidade? Educação inclusiva não é a mesma coisa que educação de qualidade? Ou, dito de outra forma: educação de qualidade não inclui a todos no processo de aprender? Anjos, Andrade e Pereira (2009) apontam para um problema que merece nossa atenção porque, nas entrelinhas, nos chama à construção da educação transformadora que responda às necessidades sociais e políticas de nosso povo. Dizem as autoras: 
regular os alunos com deficiência trouxeram à luz o fato de que concepções e práticas segregacionistas, integracionistas e inclusivistas convivem e se enfrentam no cotidiano das escolas. Pode-se atribuir tal situação ao fato de que as propostas de inclusão foram trazidas de outros países, com histórias diferenciadas de atendimento à deficiência, muitas vezes ignorando o trajeto real da educação especial no Brasil. (Idem, p. 118).

O fato de que as propostas de inclusão foram trazidas de outros países poderia significar que ignoramos os direitos dos humanos em relação à educação e que apenas seguimos imitando. Não é bem verdade. $\mathrm{O}$ que tem sido omitido - ou, pelo menos, pouco evidenciado - é o fato de que os movimentos sociais populares no Brasil têm feito progredir a função legisladora do Estado como garantidor dos direitos, no que se refere tanto às denúncias contra as injustiças quanto às reivindicações por cumprimento das leis. São os movimentos sociais populares que nos retiram da zona confortável de sermos um país avançado em relação às conquistas de direitos para os humanos - e para os animais também.

Quando Mendes (2006) interpreta a história da escolarização das crianças e jovens com deficiência no Brasil, lembra que, a partir da década de 1970, a sociedade já questionava a segregação dos alunos em classes especiais. Havia a crença (e não há mais?) de que os alunos se sentiam mais bem atendidos quando estavam entre os seus iguais, em ambientes separados. Em estudo realizado na década de 1990 (PADILHA, 2004), descrevo e analiso o encaminhamento das crianças às classes especiais para deficientes, concluindo àquela época (não tão distante):

Nosso exame da rede de encaminhamento das crianças para as classes especiais nos leva a reiterar a necessidade urgente de transformações conceituais dos agentes que trabalham na área da saúde e daqueles que, nas universidades, são corresponsáveis pela formação desses profissionais e pela multiplicação dos tipos de signo e operações de interpretação implicados nos testes e diagnósticos. [...] trata-se de uma necessidade premente de revisão de 
critérios que se fazem presentes nos discursos oficiais e que legitimam as decisões cotidianas sobre "normalidade" e "deficiência" (p. 113).

Não paramos de reivindicar e propor direitos ainda não conquistados; não paramos de lutar pelos já conquistados na letra da lei. Necessitamos continuar a discussão para a transformação, não apenas em relação aos conceitos de cada um dos indivíduos ou mesmo de grupos - ainda que sem isso nada se avance -, mas também para a geração de propostas efetivas, reflexões, estudos e currículos transformadores e revolucionários; o que não acontecerá sem a consciência de que a educação é um bem inalienável e sem a consciência de que nós é que construímos e reconstruímos a vida material e, portanto, a materialidade das práticas sociais, entre elas, as práticas pedagógicas e a educação que ensine a todos. Sem essa consciência e essa ideação, ficaremos rodando no mesmo círculo vicioso ou avançando pouco. Conforme Marx e Engels (1996), pensadores que fundamentam muitas de nossas reflexões neste texto: "Não é a consciência que determina a vida, mas a vida que determina a consciência" (p. 37). Não se deve partir do que os homens dizem ou representam, ou mesmo imaginam - como no idealismo, mas, considerar os homens reais, históricos e culturais, que, "ao desenvolverem sua produção material e seu intercâmbio material, transformam também, com essa sua realidade, seu pensar e os produtos de seu pensar” (Idem, p. 37).

Maria Benevides (19--), socióloga e estudiosa dos direitos humanos, alerta para o fato de que os direitos fundamentais já proclamados não podem ser revogados por nenhuma outra decisão posterior. É o que temos dito em relação ao direito à educação e à escola para as crianças e jovens deficientes. A segregação é perniciosa e intolerável. No entanto, essa constatação não basta para a efetiva garantia de equidade.

O processo de exclusão tem absoluta relação de interdependência com as desigualdades sociais que hoje se apresentam com outras faces e por vezes com faces que são máscaras. O direito inalienável à educação de todos ainda está 
por acontecer. Não cairá do céu, como um maná dos deuses; não virá apenas da legislação; não se imporá como norma a ser cumprida pelas escolas e pelos professores. Virá da luta popular, virá da luta dos educadores por melhor formação nas universidades; virá da luta política por condições dignas de trabalho dos professores; por forte resistência contra o recuo da teoria que vem sendo imposto pelos ideários pós-modernos do "aprender a aprender", relegando a papel secundário a formação clássica e rigorosa dos profissionais da educação, como bem discute Duarte (2003; 2004; 2011).

Estamos iludidos, diz Duarte (2003): ilusões que se concretizam em formulações tais como: a) o conhecimento está disponível para todos, pela escola, pela informática, pela internet; b) a habilidade de mobilizar conhecimentos é mais importante que adquirir conhecimentos; c) os conhecimentos são todos iguais, têm o mesmo valor, não havendo entre eles uma hierarquia; d) apelar para a consciência dos alunos e professores, por meio de palavras e bons exemplos, bastaria para acabar com a violência, as guerras e as desigualdades e para gerar tolerância. Mas o homem não se faz naturalmente, afirma Saviani (2003),

ele não nasce sabendo ser homem, vale dizer, ele não nasce sabendo sentir, pensar, avaliar, agir. Para saber pensar e sentir; para saber querer, agir ou avaliar é preciso aprender, o que implica o trabalho educativo. Assim, o saber que diretamente interessa à educação é aquele que emerge como resultado do processo de aprendizagem, como resultado do trabalho educativo (p. 11).

Facci, Meira e Tuleski (2012) falam da ilusão da inclusão, "que permite considerar como incluídos alunos que permanecem na escola, mas não se apropriam de fato dos conhecimentos historicamente acumulados pelo gênero humano" (p. 15).

Não há como separar aspectos políticos dos sociais e educacionais. Graves são as palavras de Mézsáros, que, em seu livro A Educação para além do capital (2005), afirma que "cair na tentação dos reparos institucionais formais 'passo a passo' como afirma a sabedoria reformista desde 
tempos imemoriais - significa permanecer aprisionado dentro do círculo vicioso institucionalmente articulado e protegido dessa lógica autocentrada do capital" (p. 48 - grifo meu). A lógica do capital impede a criação de alternativas significativamente diferentes - uma educação que transforme o trabalhador em um agente político, que, porque pensa e age, sabe usar a palavra e seus atos como armas de transformação do mundo; que possa assumir o comando, parafraseando Bertold Brecht (2012, p. 154).

\section{LACUNAS NA FORMAÇÃO DE PROFESSORES: CONTRA OS MODISMOS, O RIGOR TEÓRICO}

Na reunião com os professores de que falei no início deste texto, outros enunciados chamam a atenção: "Estamos cansados de modismos na formação continuada e ainda temos que escrever sobre esses modismos nos concursos públicos, caso contrário a gente não passa”. Grave denúncia. Sério comprometimento em relação à participação desses professores nas discussões teóricas, absolutamente necessária às transformações da realidade objetiva. "É uma ilusão e um erro supor que o 'melhoramento' ético seja puramente individual”, diz Gramsci (1989, p. 47 - grifo do autor). Trata-se da construção de uma história de formação de professores que saibam, como explica Saviani (2003, p. 47), que "o professor lida com o indivíduo concreto que é a síntese de inúmeras relações sociais”. Sua conceituação de educação se apresenta hoje como uma das mais claras e instigadoras: o conhecimento é condição para que cada ser humano se torne ser cultural.

O trabalho educativo é o ato de produzir, direta e intencionalmente, em cada indivíduo singular, a humanidade que é produzida histórica e coletivamente pelo conjunto dos homens. Assim, o objeto da educação diz respeito, de um lado, à identificação dos elementos culturais que precisam ser assimilados pelos indivíduos da espécie humana para que eles se tornem humanos e, de outro lado e concomitantemente, à descoberta das formas 
mais adequadas para atingir esse objetivo (SAVIANI, 2003, p. 13).

A mesma lógica pode, acertadamente, ser aplicada à formação dos professores em relação à educação inclusiva da qual estamos falando e defendendo, mesmo que, necessariamente, polemizando a discussão. $\mathrm{Na}$ formação dos professores, faz-se urgente que estejam presentes elementos culturais que precisam ser assimilados por todos eles e é necessário que se consiga construir formas adequadas para atingir esse objetivo. Desse modo, não é possível que se continue a diminuir conteúdos nos cursos de formação, como pregam os ideários pedagógicos pós-modernos, nem que a escola seja palco de modismos pedagógicos sem fundamentação teórica sólida.

No Caderno de Educação Especial, publicado pelo Ministério da Educação (2012), dedicado à alfabetização de crianças com deficiência em uma proposta inclusiva, está escrito na Introdução que "a inclusão traz como eixo norteador a legitimação da diferença (diferentes práticas pedagógicas) em uma mesma sala de aula para que o aluno com deficiência possa acessar o objeto de conhecimento”. Indica-se que o verbo "acessar" diz respeito ao acesso ao conhecimento por parte dos alunos, por outras vias, alternativas. Tal recomendação pede uma análise.

Não há como negar que os alunos têm direito de acesso aos conhecimentos, ou seja, que consigam aprender o que cabe à escola ensinar. Mas é necessário definir qual conhecimento e como ter acesso a eles. De quais conhecimentos precisa o professor para saber de quais conhecimentos precisam os alunos? De que vias alternativas precisam se apropriar os professores? De uma coisa estejamos certos: não é possível termos conhecimentos necessários e estratégias especiais sem um altíssimo nível de formação teórica.

Para as crianças e jovens que necessitam de caminhos alternativos para vencer as limitações impostas - ou pelo biológico ou pelo contexto social estigmatizador -, a 
maior dificuldade é desligar-se do que está presente e do que é sensível, portanto, do seu cotidiano imediato. Reside aí, justamente, o trabalho pedagógico. Vygotski (1997), quando fala do trabalho educativo para e com as crianças deficientes, afirma:

Precisamente porque a criança com atraso mental depende tanto, em sua experiência, das impressões concretas visuais e desenvolve tão pouco por sua própria conta o pensamento abstrato, a escola deve libertá-la do excesso do método visual-direto que serve de obstáculo ao desenvolvimento do pensamento abstrato e educar esses processos. Dito de outra forma, a escola não só deve adaptar-se às insuficiências dessa criança, senão também lutar contra elas, superá-las (p. 36 - negrito nosso).

O autor está falando da organização didática fundamentada em uma concepção de aprendizado e desenvolvimento que caminha na contramão da noção de adaptação, pelo menos em dois sentidos. Um deles refere-se ao fato de que o desenvolvimento da atividade consciente do homem não se dá, essencialmente, por processo adaptativo - como ocorre com os animais - porque, pela linguagem e pelo trabalho, o homem ultrapassa as impressões sensíveis imediatas das situações exteriores, ou seja, o excesso de impressões concretas visuais muito presentes nas propostas didáticas para a educação especial. Outro sentido é o de que a organização do trabalho pedagógico deverá prever, sistematicamente e intencionalmente, atividades que promovam o desenvolvimento das funções superiores, que, para Vigotski, são as culturais.

Padilha e Oliveira (2013) argumentam que encontramos nos trabalhos reunidos em Fundamentos da Defectologia, escritos entre 1924 e 1934 por Vygotski, um importante aporte para compreendermos o papel da instrução no desenvolvimento das crianças. Questionando a escola de sua época - e não estaríamos equivocados se aproximássemos tais críticas ao nosso tempo - disse ele que a escola comum colocava barreiras quando selecionava os alunos que não podiam estar nela. 
Para este autor, tal seleção impede o desenvolvimento das muitas formas de desenvolver e aprender desses indivíduos, além de revelar o desconhecimento teórico sobre o que é a deficiência e principalmente sobre a lei geral do desenvolvimento humano; para ele a premissa central: as mesmas leis que regem o desenvolvimento das crianças deficientes regem o desenvolvimento das que não são deficientes. Denuncia que as características negativas e as complicações da deficiência não estão no biológico ou na própria deficiência em sua forma primária, biológica, mas são fruto do "[...] desenvolvimento social incompleto, de uma negligência pedagógica” (VYGOTSKI, 1997, p. 144). Padilha e Oliveira (2013) abordam a questão da seguinte forma:

\begin{abstract}
Sem negar a base orgânica do desenvolvimento, Vigotski sustenta a importância de um biológico que é social e cultural. Suas teorias sobre o desenvolvimento da criança, sobre a elaboração conceitual e o papel da escola nos ajudam a fundamentar duas noções que podem direcionar o entendimento que temos acerca de diversidade e desigualdade, no que se refere, especificamente, à educação das crianças pequenas. São elas: singularidade e necessidade. (p. 132 - grifos dos autores).
\end{abstract}

Reconhecendo a escola como lugar de passagem do conhecimento cotidiano para o conhecimento científico e conhecendo os alunos e suas necessidades, são exigências do trabalho pedagógico: prover a sala de aula de condições para que todos possam dela participar; priorizar, promover e acompanhar o desenvolvimento das funções psicológicas superiores (linguagem, cálculo, imaginação, atenção, memória, percepção, comparação, imitação, leitura, escrita etc.); preparar situações de aprendizado, organizando-as; trabalhar em conjunto com os outros professores da unidade escolar; observar e registrar os avanços e recuos para (re)planejar suas ações - porque a atividade pedagógica é construção das pessoas que dela fazem parte e que nela aprendem.

Ainda na direção de refletir sobre os modos de organizar o trabalho pedagógico, podemos nos apropriar de um importante ensinamento de Vigotski (1993) quando 
explicita que "se o curso do desenvolvimento coincidisse por completo com o da instrução, cada momento desta última teria igual importância para o desenvolvimento" (p. 236). O desenvolvimento, no entanto, acontece em um ritmo distinto do ritmo da instrução. O desenvolvimento não se subordina ao programa escolar, por ter sua lógica interna. Não há, pois, coincidência entre esses dois processos. Quando se está ensinando, está apenas começando a elaboração do conceito - "a instrução se adianta, no fundamental, ao desenvolvimento” (p. 237).

$\mathrm{Na}$ perspectiva histórico-cultural, encontramos um conceito de fundamental importância: o de mediação. A palavra mediação é também polissêmica - como todas as palavras - e é por isso necessário explicitar o sentido dela nesta perspectiva: processo de significação. $O$ conceito de mediação pressupõe o conceito de cultura como o conjunto das produções humanas que, por definição, são portadoras de significação, ou seja, na medida em que as ações vão sendo significadas pelo outro - pode-se falar aqui da relação de ensino -, há conversões da significação que acontecem nas relações sociais. $\mathrm{O}$ que o aluno transfere para a esfera intrapsíquica não são as palavras, são as suas significações; não são as ações, são as suas significações. A interiorização das significações que vão se constituindo nas relações historicamente construídas, ou seja, a internalização das formas culturais complexas ou superiores vai acontecendo no processo de aprendizado.

A significação não está pronta como um prato a ser servido; os significados das palavras são formações dinâmicas e evoluem ao longo do processo histórico da humanidade; do processo da vida de cada indivíduo; da dinâmica das aulas, na escola. É na circulação, elaboração e reelaboração de significados concretizados na escola que acontece a formação de conceitos e que, não menos importante, a palavra, signo por excelência, permite transformar o que é alheio à criança em algo próprio dela. $\mathrm{O}$ conceito de mediação tem sido equivocadamente compreendido também quando se trata da escola - e interpretado apenas 
como qualquer ajuda do outro. Mas o professor é sempre mediador, está sempre, de alguma forma, organizando sua prática e dirigindo-se aos seus alunos. O problema está em identificar o que é a mediação e qual a sua qualidade, e estabelecer seus métodos e objetivos, pois ela pode ou não proporcionar a apropriação dos conhecimentos desejados (PADILHA; JOLY, 2009).

\section{Algumas CONSIDERAÇÕes Finais: MAS NÃO MENOS IMPORTANTES}

O que diremos à professora que apresentei no início deste texto? Já falamos muito de educação inclusiva e nada fizemos? É isso? Muito se tem estudado e pesquisado e caminhamos, sim - nossa concepção de sujeito, de sociedade, de educação, de direitos humanos e de deficiência vem se ampliando, mesmo que por caminhos nem sempre fáceis e sem obstáculos. Mas foi sempre assim. As grandes conquistas sociais demandam consciência, desejo, organização, estudo, planejamento, avaliação constante e estado permanente de alerta. Não é o que estamos vivendo - nos movimentos sociais populares - em relação à luta contra os preconceitos e os estigmas a que estão sujeitos vários grupos sociais - nem sempre minoritários?

Reflitamos sobre a necessidade de apropriação de conhecimentos para que nos afastemos cada vez mais do mito de que a diferença precisa apenas ser "aceita e respeitada”. Não é questão de aceitar ou não aceitar; respeitar ou não respeitar. Vamos muito além: trata-se de uma questão constitutiva do humano. Angel Pino (2005), pensador e estudioso do desenvolvimento humano na perspectiva históricocultural, instiga a pensar sobre por que a educação deve ser para todos, e o faz indo às raízes do pensamento humano. Explica ele que, desde os primeiros instantes da existência do humano, a cultura entra em ação; em outras palavras, confere "às ações do bebê humano um caráter cada vez menos automático ou instintivo e cada vez mais imitativo e deliberativo" (p. 45). Significa que há um novo nascimento, 
uma nova história a ser vivida após o nascimento que, tendo por base material o biológico, mas não conseguindo a emergência das funções definidoras do humano apenas com esse material, necessita do outro humano, necessita do meio humano, da educação. A atribuição da significação às coisas do mundo e das pessoas do mundo é tarefa da mediação social, portanto, da ação da cultura, então, da mediação do outro, da mediação social, do processo da educação.

Quando tomamos decisões sobre o que devemos fazer, quando optamos ou escolhemos um caminho, um conteúdo e uma forma de ação, é preciso um empenho epistemológico e metodológico, no sentido de responder às questões que se nos apresentam de uma forma tal que o que queremos fique explicitado e fundamentado, considerando igualmente importante que determinemos com clareza o que não queremos. Esse saber nos torna mais críticos e mais fiéis às concepções assumidas. Quando determinamos o que não queremos, estamos aptos a nos libertar das armadilhas das boas intenções apenas; das propagandas enganosas; das resoluções das políticas públicas que se apresentam de forma simplista com soluções que se anunciam como salvadoras da miséria e da injustiça, a favor do direito e da cidadania.

O preconceito ainda se constitui como impedimento à educação que se quer para todos. Um dos caminhos contrários ao preconceito pode ser pela via do conhecimento teórico e da instrumentalização técnica dos profissionais da educação, levando-se em conta a interdependência entre teoria e prática. Ressalta-se a importância de dar a conhecer aos alunos dos cursos de Pedagogia, de licenciaturas e de formação de psicólogos e fonoaudiólogos, os resultados das pesquisas que indiciam e evidenciam as possibilidades de vencer os limites, tanto os impostos pelas deficiências quanto os introjetados pelas relações concretas de vida social.

Até onde é preciso expandir as pesquisas, os estudos, as ações, as propostas para que se possa construir uma sociedade emancipada? As soluções não podem ser formais (apenas e/ou prioritariamente), mas devem ser 
essenciais - abarcar a totalidade das práticas porque, ainda que formalmente haja leis e resoluções, há uma enorme probabilidade de inversões, enquanto a lógica capitalista neoliberal permanecer sem ser alterada.

Nossas pesquisas precisam ir além das constatações, mesmo reconhecendo que elas são necessárias ao conhecimento da realidade; precisam ir além das críticas, ainda que sem elas não se abram caminhos alternativos. O simples acesso à escola não é suficiente, ainda que muitíssimo necessário.

O Brasil e nós brasileiros ficamos de 1964 até 1985 sob um regime militar e antidemocrático. A (re)construção da democracia vem, desde então, ora engatinhando, ora ensaiando alguns passos, mas com muitas dificuldades. Se conseguimos voltar a ter o direito de voto e de organização, falta-nos muito para sermos uma nação democrática - falta a participação popular que vai além do depósito dos votos na urna; além do acesso às informações pelos meios de comunicação. É desse lugar que queremos abordar o tema da exclusão ou inclusão social, exclusão ou inclusão escolar.

Frigotto (2000) evidencia que

Buscar entender adequadamente os dilemas e impasses do campo educativo, hoje, é, inicialmente, dispor-se a entender que a crise da educação somente é possível de ser compreendida no escopo mais amplo da crise do capitalismo real $[\ldots]$, no plano internacional e com especificidades no nosso país. Trata-se de uma crise que está marcada por uma especificidade que se explicita nos planos econômico-social, ideológico, ético-político e educacional, cuja análise fica mutilada pela crise teórica (p. $79-$ grifos do autor).

O foco das análises, apenas indicadas neste texto, mostra a contradição entre o discurso da inclusão social presente nos documentos oficiais e veiculados pelos meios de comunicação e aquele que nos exige o estudo mais aprofundado sobre os determinantes históricos e sociais da vida dos povos e de seus grupos sociais.

Enquanto acreditarmos ingenuamente que é suficiente que alguns indivíduos, grupos ou comunidades - que se

Educação inclusiva: já se falou muito sobre ela? 
colocam como possuidores de poder e decisão - assumam o discurso de que a escola é para todos ou que os deficientes são legalmente respeitados em suas peculiares necessidades, e, ainda, que as diferentes etnias e orientações sexuais têm os mesmos direitos e que, para tanto, o Estado tem proposto resoluções e promulgado leis que os garantam, enquanto assim acreditarmos, não poderemos caminhar muito bem em direção a uma efetiva conquista do que vem sendo chamado de sistema democrático ou sociedade inclusiva e, consequentemente, escola inclusiva.

À professora que está desanimada porque "nada acontece”, insisto: "O desenvolvimento incompleto das funções superiores está ligado ao desenvolvimento cultural incompleto". E a causa dessa incompletude é a "negligência pedagógica” (VYGOTSKI, 1997, p. 144).

\section{REFERENCIAS}

ANJOS, H. P.; ANDRADE, E. P.; PEREIRA, M. R. A inclusão escolar do ponto de vista dos professores: o processo de constituição de um discurso. Universidade Federal do Pará, Faculdade de Educação de Marabá. Revista Brasileira de Educação, v. 14 n. 40 jan./abr. 2009, p. 116-129.

BENEVIDES, M. V. Cidadania e Direitos Humanos. Instituto de Estudos Avançados da Universidade de São Paulo. Disponível em: <http://www.iea.usp.br/publicacoes/ textos/benevidescidadaniaedireitoshumanos.pdf/at_ download/file>. Acesso em: 25 ago. 2014.

BRASIL. Ministério da Educação. Caderno de educação especial: a alfabetização de crianças com deficiência: uma proposta inclusiva. Brasília: MEC, SEB, 2012. Disponível em: <http://pacto.mec.gov.br/images/pdf/Formacao/ Educacao_Especial_MIOLO.pdf $>$. Acesso em 25 ago. 2014.

- Presidência da República. Casa Civil. Subchefia para Assuntos Jurídicos. Decreto n ${ }^{\circ}$ 99.710, de 21 de novembro de 1990. Promulga a Convenção sobre os Direitos da Criança. Disponível em: <http://www.planalto.gov.br/ 
ccivil_03/decreto/1990-1994/D99710.htm >. Acesso em: 25 ago. 2014.

. Decreto $\mathrm{n}^{\circ} 6.949$, de 25 de agosto de 2009. Promulga a Convenção Internacional sobre os Direitos das Pessoas com Deficiência e seu Protocolo Facultativo, assinados em Nova York, em 30 de março de 2007. Disponível em: <http://www.planalto.gov.br/ccivil_03/_ato20072010/2009/decreto/d6949.htm >. Acesso em: 25 ago. 2014.

. Lei no 8.069 , de 13 de julho de 1990. Texto compilado. Dispõe sobre o Estatuto da Criança e do Adolescente e dá outras providências. Disponível em: <http://www.planalto. gov.br/ccivil_03/leis/18069.htm >. Acesso em: 25 ago. 2014.

. Lei ${ }^{\circ} 10.741$, de $1^{\circ}$ de outubro de 2003. Dispõe sobre o Estatuto do Idoso e dá outras providências. Disponível em: <http://www.planalto.gov.br/ccivil_03/ leis/2003/110.741.htm>. Acesso em: 25 ago. 2014.

. Lei $\mathrm{n}^{\circ} 11.340$, de 7 de agosto de 2006. Cria mecanismos para coibir a violência doméstica e familiar contra a mulher, nos termos do $\mathbb{8} 8$ o do art. 226 da Constituição Federal, da Convenção sobre a Eliminação de Todas as Formas de Discriminação contra as Mulheres e da Convenção Interamericana para Prevenir, Punir e Erradicar a Violência contra a Mulher; dispõe sobre a criação dos Juizados de Violência Doméstica e Familiar contra a Mulher; altera o Código de Processo Penal, o Código Penal e a Lei de Execução Penal; e dá outras providências. Disponível em: <http://www.planalto.gov.br/ccivil_03/_ato20042006/2006/lei/111340.htm >. Acesso em: 25 ago. 2014.

. Constituição da República Federativa do Brasil de 1988. Disponível em: <http://www.planalto.gov.br/ ccivil_03/constituicao/constituicao.htm>. Acesso em: 25 ago. 2014 .

. Lei n ${ }^{\circ} 9.394$, de 20 de dezembro de 1996. Estabelece as diretrizes e bases da educação nacional. Disponível em: <http://www.planalto.gov.br/ccivil_03/leis/19394.htm>. Acesso em 25 ago. 2014.

Educ. Foco, Juiz de Fora, 
BRECHT, B. Poemas (1913 - 1956). 7. ed. São Paulo: Editora 34, 2012.

DECLARAÇÃO de Salamanca. Sobre Princípios, Políticas e Práticas na Área das Necessidades Educativas Especiais. Disponível em: <http://unesdoc.unesco.org/images/ 0013/001393/139394por.pdf>. Acesso em 25 ago. 2014.

DECLARAÇÃO mundial sobre educação para todos: satisfação das necessidades básicas de aprendizagem. Jomtien, 1990. UNESCO. Resources. Disponível em: <http:// unesdoc.unesco.org/images/0008/000862/086291por.pdf $>$. Acesso em: 25 ago. 2014.

DECLARAÇÃO Universal dos Direitos Humanos. Adotada e proclamada pela resolução 217 A (III) da Assembleia Geral das Nações Unidas em 10 de dezembro de 1948. Disponível em: <http://portal.mj.gov.br/sedh/ct/legis_ intern/ddh_bib_inter_universal.htm $>$. Acesso em: 25 ago. 2014.

FACCI, M. G. D.; MEIRA, M. E. M.; TUlESKI, S. C. Apresentação. In: FACCI, M. G. D.; MEIRA, M. E. M.; TULESKI, S.C. A exclusão dos "incluídos": uma crítica da Psicologia da Educação à patologização e medicalização dos processos educativos. Maringá: EUEM, 2012, p. 15-18 FRIGOTTO, G. Os delírios da razão: crise do capital e metamorfose conceitual no campo educacional. In: GENTILI, P. (Org.). Pedagogia da exclusão: crítica ao neoliberalismo na educação. São Paulo: Vozes, 2000. p. 77-108.

GRAMSCI, A. Concepção Dialética da História. 8. ed. Rio de Janeiro: Civilização Brasileira, 1989.

MARX, K; ENGELS, F. A Ideologia Alemã. São Paulo: Hucitec, 1996.

MENDES, E. G. A radicalização do debate sobre inclusão escolar no Brasil. Universidade Federal de São Carlos, Programa de Pós-Graduação em Educação Especial. Revista 
MÉSZÁROS, I. A educação para além do capital. São Paulo: Boitempo, 2005.

PACTO Internacional dos Direitos Econômicos, Sociais e Culturais. Adotado pela Resolução n. 2.200-A (XXI) da Assembleia Geral das Nações Unidas, em 16 de dezembro de 1966 e ratificada pelo Brasil em 24 de janeiro de 1992. Washington: Organization of American States. Disponível em: <http://www.oas.org/dil/port/1966 Pacto Internacional sobre os Direitos Económicos, Sociais e Culturais.pdf >. Acesso em: 25 ago. 2014.

PADILHA, A. M. L. Possibilidades de histórias ao contrário ou como desencaminhar o aluno da classe especial. São Paulo: Plexus/Summus, 2004.

; JOLY, M. M. Conhecimento e prática pedagógica no processo de aquisição de leitura. In: XVII Congresso de Leitura do Brasil (COLE), 2009, Campinas. Anais... Campinas: ALB, 2009. Disponível em: <http://www.alb. com.br/portal.html>. Acesso em: 12 jul. 2014.

; OLIVEIRA, I. M. Quando diversidade (não) é o mesmo que desigualdade: educação infantil e trabalho docente. In: RANGEL, I. S.; NUNES, K. R.; CÔCO, V. (Org.). Educação Infantil: rede de conversações e produções de sentidos com crianças e adultos. Petrópolis: De Petrus, 2013.

PINO, A. As Marcas do Humano: às origens da constituição cultural da criança na perspectiva de Lev S. Vigotski. São Paulo: Cortez, 2005.

SAVIANI, Dermeval. Entrevista com Dermeval Saviani sobre o Plano Nacional de Educação (PNE). Rio de Janeiro: Associação Nacional de Pesquisadores em Educação (ANPED). Disponível em: <http://www.anped.org.br/ news/entrevista-com-dermeval-saviani-pne $>$. Acesso em 10 ago. 2014.

VYGOTSKI, L. S. Obras Escogidas. v. 2. Madrid: Visor, 1993. . Obras Escogidas. v. 3. Madrid: Visor, 1995. 
Madrid: Visor, 1997.

WAISELFISZ, J. J. Mapa da violência. Rio de Janeiro / São Paulo: Centro Brasileiro de Estudos Latino-americanos / Faculdade Latino-Americana de Ciências Sociais - Brasil. Disponível em: <http://www.mapadaviolencia.org.br/>. Acesso em: 25 ago. 2014.

\section{INCLUSIVE EDUCATION: HAS ENOUGH BEEN SAID ABOUT IT?}

The purpose of this paper is to provide elements for a critical reflection on what is nowadays named inclusive education, in the sense of attracting attention to some aspects, such as: every children's and youngsters' right to quality education; the misunderstandings of inclusion; the gaps in the teacher's qualification, and the necessary theoretical contributions for the accomplishment of education for all. The fact that there are laws and resolutions which assure a universal school education, free from charges and secular for all and including the handicapped ones, has not been assuring the quality teaching, that is, the learning of knowledge historically accumulated by mankind. Elementary school teachers give clues stating that the qualification they are receiving does not account for their professional needs. The act of thinking the inclusive education demands knowing our social and political reality, as well as mastering theoretical knowledge with epistemological strictness on the human development and on the role of the school as an educational act. As theoretical frames we have taken Carl Marx's and Friedrich Engels' philosophy, Lev Semionovich Vigotski's historical-cultural perspective of development, and Dermeval Saviani's historical-critical pedagogy.

Keywords: Inclusive Education. Right to Education. Teacher Training. 